\title{
Light Scattering Studies of Hydration and Structural Transformations of Lysozyme
}

\author{
A. SzYMańska and G. ŚlósAREK* \\ Department of Molecular Biophysics, Faculty of Physics, Adam Mickiewicz University \\ Umultowska 85, 61-614 Poznań, Poland
}

(Received October 7, 2010; in final form October 12, 2011)

\begin{abstract}
We have applied the method of dynamic light scattering to analyse the lysozyme-ethanol interaction. For low ethanol concentration (below $4.3 \%(\mathrm{v} / \mathrm{v})$ ) no chemical denaturation process is observed. When the ethanol concentration grows above the triggering concentration the hydrodynamic radius of lysozyme increases, indicating the structural changes within the protein molecule. The observed structural modifications are attributed to dehydration and preliminary tertiary structure modification of the protein molecule.
\end{abstract}

PACS: 87.15.kr, 34.50.-s

\section{Introduction}

Considerable attention is presently focused on studies on folding and aggregation of proteins. About twenty protein molecules are known to be involved in human diseases with that kind of pathology [1, 2]. In 1993 Pepys et al. identified mutations in human lysozyme associated with amyloidosis [3]. Since then a large number of the experimental studies on amyloid formation concern the molecule exctracted from hen egg white lysozyme (HEWL) as well as other molecules from lysozyme family [4]. Among others HEWL can form ordered aggregates in water-ethanol solutions [5-8]. The amyloid structure construction is preceded by the partial denaturation of the protein and formation of an intermediate structural state $[5,9]$. In this paper we present the analysis of the preliminary steps of this process.

Experiments which are based on the phenomenon of radiation scattering are usually applied in the analysis of size and intermolecular interaction of macromolecules $[10,11]$. Light scattering (static - SLS and dynamic DLS), small-angle X-ray scattering (SAXS), and small-angle neutron scattering (SANS) form a group of the methods of choice in the study of intermolecular interactions in colloidal suspension. In protein solutions interesting problems concern the phenomena of hydration and aggregation. Formation of a protein hydration shell is a fundamental condition for the native structure stabilization, intermolecular interaction, and aggregation. Any modification in hydration shell of a protein molecule

\footnotetext{
* corresponding author; e-mail: leonardo@amu.edu.pl
}

strongly influences its biological function. Among others alcohol molecules, when added to colloidal suspension, compete with water molecules for the position on the surface of a protein molecule. Presence of the alcohol molecules disturbs an equilibrium among hydrophobic chemical groups of a protein and finally leads to destruction of its native, tertiary structure [12]. The experiments based on radiation scattering together with computer simulations [13] enable determination of the size and structure of the hydration shell.

We have applied dynamic light scattering methods for the analysis of the properties of HEWL. This is a very well known protein molecule, the enzyme consisting of 129 amino acid residues [14]. It folds into two structural domains, $\alpha$ (since it includes four $\alpha$ helical fragments) and $\beta$ (since it includes two $\beta$ strands). Four disulfide bonds stabilize its native structure. The lysozyme structure, enzyme activity as well as hydration have been studied by crystallographic and NMR structural analysis for a long time [15]. Other studies concern hydrodynamic properties of the protein. Partial specific volume $\left(v=0.7126 \mathrm{~cm}^{3} / \mathrm{g}[16]\right)$ sedimentation coefficient $\left(s=1.91 \times 10^{-13} \mathrm{~s}[17]\right)$ as well as translational (Table) and rotational $\left(D_{\mathrm{R}}=16.7 \times 10^{6} \mathrm{~s}^{-1}[18]\right)$ diffusion coefficients have been determined.

In this paper we present the application of DLS in the analysis of the influence of the ethanol molecules and salt ions on the lysozyme structure. We shall determine the initial stage of the protein denaturation caused by ethanol molecules. Similar studies were performed before [20]. According to the data presented in that paper, with the increase of the ethanol concentration the hydrodynamic radius $R_{\mathrm{H}}$ of the protein initially decreases and 
reaches a minimum, and only then increases. The change of $R_{\mathrm{H}}$ is compared with the change of partial molar volumes of ethanol in water/ethanol mixtures. The authors suggest that the protein molecule plays a role of a very sensible probe for the water/ethanol interactions.

TABLE

Translational self-diffusion coefficient $D_{\mathrm{T}}$ for lysozyme molecule suspended in water solution.

\begin{tabular}{c|c|c}
\hline \hline $\begin{array}{c}\text { Diffusion coefficient } \\
{\left[10^{-10} \mathrm{~m}^{2} / \mathrm{s}\right]}\end{array}$ & Experimental conditions & Reference \\
\hline 1.10 & water, $1.35 \mathrm{M}\left(\mathrm{NH}_{4}\right)_{2} \mathrm{SO}_{4} ; \mathrm{pH} 6.7$ & {$[17]$} \\
$1.06 \pm 0.01$ & water, $100 \mathrm{mM}$ sodium acetate - acetic acid buffer, $\mathrm{pH} 4.2$ & {$[18]$} \\
$1.13 \pm 0.02$ & water, $45 \mathrm{mM}$ acetate bufer; $\mathrm{pH} 4.15$ & {$[19]$} \\
$0.086 \pm 0.02$ & water, $45 \mathrm{mM}$ acetate bufer, glycerol $60 \%(\mathrm{v} / \mathrm{v}) ; \mathrm{pH} 4.3$ & {$[20]$} \\
$1.05 \pm 0.01$ & water, $100 \mathrm{mM}$ glycine; $\mathrm{pH} 3$ & {$[21]$} \\
$1.03 \pm 0.03$ & water; $\mathrm{pH} 6.7 \pm 0.2$ &
\end{tabular}

\section{Basic theoretical considerations}

Light scattering is most easily observed when the radiation interacts with molecules of a colloidal suspension. Dynamic light scattering methods are based on the analysis of temporal correlation of the intensity of the light scattered by colloidal particles. The scattered light intensity autocorrelation function decays exponentially with the time constant $\tau$ - correlation time,

$$
\tau=\frac{1}{2 D_{\mathrm{T}} q^{2}},
$$

where $q$ denotes the scattering wave vector

$$
q=\left(\frac{4 \pi n}{\lambda}\right) \sin \left(\frac{\vartheta}{2}\right)
$$

$\left(\vartheta\right.$ - scattering angle) and $D_{\mathrm{T}}$ - the collective translational diffusion coefficient. A self-diffusion coefficient $D_{\mathrm{T} 0}$ is described by the Stokes-Einstein equation

$$
D_{\mathrm{T} 0}=\frac{k T}{6 \pi \eta R_{\mathrm{H}}},
$$

where $R_{\mathrm{H}}$ denotes the radius of a sphere hydrodynamically equivalent to a colloidal particle in the solution, $\eta$ - viscosity coefficient, $T$ - temperature, $k$ - the Boltzmann constant. All particles, protein macromolecules as well, when suspended in a water solution possess a hydration shell. On the basis of various experimental data it is assumed that the average thickness of the hydration shell equals $0.3 \mathrm{~nm}[18]$. In determination of hydrodynamic radius, the hydration shell volume should be taken into account. This concerns in general only that part of the hydration shell where water molecules are strongly bound to the macromolecule surface and the binding time is long in comparison to the time of the macromolecule light interaction.

\section{Materials and methods}

Hen egg white lysozyme (EC 3.2.1.17) was purchased from SIGMA. The protein stock solution (with the protein concentration of about $20 \mathrm{mg} / \mathrm{ml}$ ) has been prepared by dissolution of lysozyme in deionised water from Barnstead filtering device. The appropriate volumes of the stock solution and $96 \%(\mathrm{v} / \mathrm{v})$ water-ethanol mixture were brought together in order to prepare the working solutions with proper concentration $c_{\mathrm{EtOH}}(0 \div 10 \%(\mathrm{v} / \mathrm{v}))$ and $c_{\mathrm{NaCl}}\left(0 \div 50 \mathrm{mmol} \mathrm{dm}^{-3}\right)$. Final $\mathrm{HCl} \mathrm{pH}-4.5$. For light scattering experiments all samples were filtered using Millipore filter $(0.22 \mu \mathrm{m})$ and finally centrifuged at the rate of $8000 \mathrm{rpm}$ for $30 \mathrm{~min}$. Final protein concentration has been determined by UV spectroscopy (molar absorbance coefficient $\left.\varepsilon^{280 \mathrm{~nm}}=2.54 \mathrm{ml} /\left(\mathrm{mg} \mathrm{cm}^{3}\right)\right)$ [16].

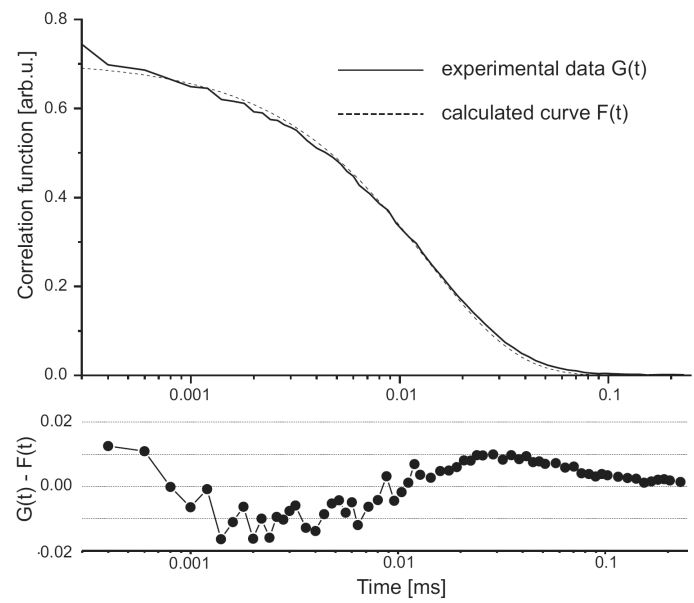

Fig. 1. Experimental correlation function $G(t)(50 \mathrm{mM}$ $\mathrm{NaCl}, \mathrm{pH}=4.5$; protein concentration $c=8.9 \mathrm{mg} / \mathrm{ml}$; $\left.c_{\mathrm{EtOH}}=9.91 \%\right)$ and calculated curve $F(t)$. Calculations were performed taking into account a single-component model. 
The setup for light scattering experiments was equipped with $\mathrm{Kr}$ laser $(\lambda=647 \mathrm{~nm})$ from Carl Zeiss, Jena, Germany. The intensity of the scattered light was measured at an angle $\vartheta=90^{\circ}$ using a correlator ALV5000 from ALV, Langen, Germany. The measurements were performed at room temperature. Experimental data were analysed using CONTIN. A single-component model was taken into account. Even in the presence of high ethanol $(9.91 \%(\mathrm{v} / \mathrm{v}))$ and salt $(50 \mathrm{mM} \mathrm{NaCl})$ concentration no deviation from this assumption was observed (Fig. 1).

\section{Results and discussion}

We have determined translational diffusion coefficient of lysozyme molecule. In the solution free from ethanol $(50 \mathrm{mM} \mathrm{NaCl}, \mathrm{pH} 4.5)$ it equals $(1.102 \pm 0.009) \times$ $10^{-10} \mathrm{~m}^{2} / \mathrm{s}$, which is in agreement with our previous data $(1.101 \pm 0.02) \times 10^{-10} \mathrm{~m}^{2} / \mathrm{s}\left(50 \mathrm{mM} \mathrm{Na} 2 \mathrm{HPO}_{4} /\right.$ $\left.\mathrm{NaH}_{2} \mathrm{PO}_{4}, \mathrm{pH} 4.5\right)$ [22] as well as with data determined by others (Table). With the increasing amount of ethanol $D_{\mathrm{T}}$ decreases (Fig. 2) as it was also observed earlier $[20,21]$. The diffusion coefficient reaches a value of $(0.689 \pm 0.011) \times 10^{-10} \mathrm{~m}^{2} / \mathrm{s}$, while the ethanol concentration increases up to $9.91 \%(\mathrm{v} / \mathrm{v})$. The diffusion coefficient decreases also with the addition of salt (Fig. 3). However, as it was presented in Fig. 1, under these conditions the aggregation of protein molecules does not take place. On the basis of studies of second viral coefficient $B_{22}$, performed using the method of SLS [23], it has been shown that $B_{22}$ increases with alcohol concentration and reaches a plateau value at concentration $\approx 5 \%(\mathrm{v} / \mathrm{v})$. The change of the $B_{22}$ value is independent of $\mathrm{NaCl}$ concentration, which means that presence of ethanol molecules does not affect electrostatic protein-protein interaction.

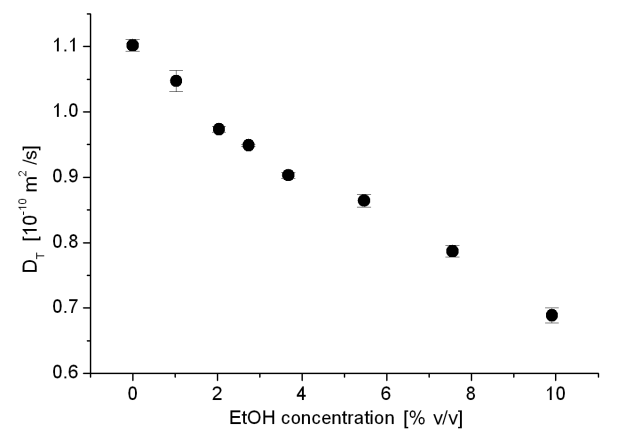

Fig. 2. Translational diffusion coefficient of lysozyme in water-ethanol $(50 \mathrm{mM} \mathrm{NaCl}, \mathrm{pH} 4.5)$ solutions as a function of ethanol concentration.

Changes of the diffusion coefficient, presented above, could be attributed to the increasing viscosity of the solvent, as it was in the water-glycerol solutions [24] or to the denaturation process, as it was observed in the case of temperature denaturation [25] and chemical denaturation by guanidine hydrochloride $(\mathrm{Gdn} \cdot \mathrm{HCl})[26]$. Since the viscosity of water-ethanol solution changes from $1.05 \times 10^{-3} \mathrm{~Pa} \mathrm{~s}$ (for $0 \% \mathrm{EtOH}(\mathrm{v} / \mathrm{v})$ ) to $1.21 \times 10^{-3} \mathrm{~Pa} \mathrm{~s}$

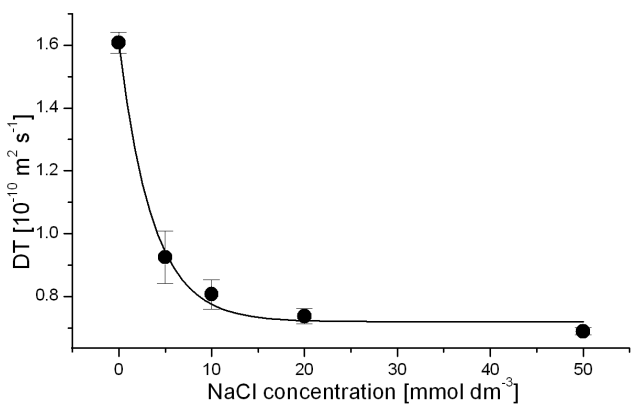

Fig. 3. Translational diffusion coefficient of lysozyme in water-ethanol solution $\left(c_{\mathrm{EtOH}}=9.91 \%(\mathrm{v} / \mathrm{v}) ; \mathrm{pH}=\right.$ $4.5)$ as a function of $\mathrm{NaCl}$ concentration. Solid line approximation function.

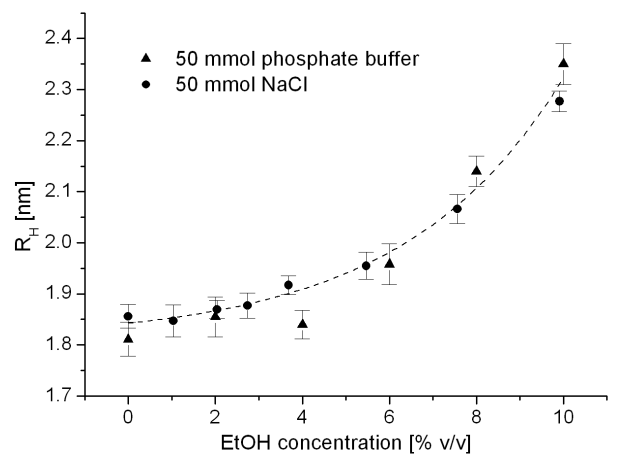

Fig. 4. Change of the hydrodynamic radius $R_{\mathrm{H}}$ of lysozyme in function of ethanol concentration in the presence of phosphate buffer (50 mM Na $2 \mathrm{HPO}_{4} /$ $\left.\mathrm{NaH}_{2} \mathrm{PO}_{4}, \mathrm{pH}=4.5\right)$ or sodium salt $(50 \mathrm{mM} \mathrm{NaCl}$, $\mathrm{pH}=4.5)$. Dashed line - approximation function.

(for $10.6 \% \mathrm{EtOH}(\mathrm{v} / \mathrm{v})$ ) [16], we assume that the observed changes are connected with the structural transformations of the protein molecule related to its dehydration.

In general, the denaturation process is described as a cooperative two-state transition from folded to unfolded state. As a consequence of thermal denaturation the diffusion coefficient decreases and the hydrodynamic radius of the protein increases by approximately 18\% [25]. In the case of chemical denaturation, when the concentration of $\mathrm{Gdn} \cdot \mathrm{HCl}$ increases from 0 to about $2 \mathrm{M}$, the diffusion coefficient of lysozyme remains constant and equals $(1.06 \pm 0.01) \times 10^{-10} \mathrm{~m}^{2} / \mathrm{s}[26]$. Within the concentration range of $\mathrm{Gdn} \cdot \mathrm{HCl}$ from $2 \mathrm{M}$ to $5 \mathrm{M}$ the diffusion coefficient decreases and finally reaches the value $(0.73 \pm 0.01) \times 10^{-10} \mathrm{~m}^{2} / \mathrm{s}$. While the concentration of $\mathrm{Gdn} \cdot \mathrm{HCl}$ further increases up to $6.5 \mathrm{M}$, it remains constant. This value could not be attributed to a fully denatured protein, while the addition of $30 \mathrm{mM}$ of dithiothreitol to lysozyme solution causes a further drop in the diffusion coefficient to $(0.57 \pm 0.02) \times 10^{-10} \mathrm{~m}^{2} / \mathrm{s}[26]$.

We have calculated the radius $R_{\mathrm{H}}$ of a sphere hydrodynamically equivalent to lysozyme molecule (3), tak- 
ing into account the change of viscosity coefficient of the water-ethanol solution [22]. The results of the calculation are presented in Fig. 4. Change of the protein size is independent of the type of anions present in the solution. It follows from our measurements that for lysozyme in aqueous solution with zero concentration of ethanol the value of the hydrodynamic radius equals $(1.856 \pm 0.023) \mathrm{nm}$, which is in a good agreement with the results known from literature (e.g. $1.811 \mathrm{~nm} \mathrm{[22],}$ $1.85 \mathrm{~nm}$ [25], $1.87 \mathrm{~nm}$ [24], $1.96 \mathrm{~nm}$ [27]). When the ethanol concentration reaches $9.91 \%(\mathrm{v} / \mathrm{v})$, hydrodynamic radius increases up to $(2.277 \pm 0.020) \mathrm{nm}$. This is different from the results obtained by Calandrini and co-workers [20], who have observed the initial decrease and then the increase of the value of $R_{\mathrm{H}}$. On the other hand, this tendency is similar to the temperature dependence of the hydration radius [25] and the radius of gyration $R_{\mathrm{g}}$ [28]. One can draw a conclusion that at the very low ethanol concentration $R_{\mathrm{H}}$ remains constant. Interaction between ethanol and protein molecules is weak with short occupation time. $R_{\mathrm{H}}$ starts to increase while the ethanol concentration reaches its critical value. Using a very simple procedure - determination of the point of intersection of two lines: $y=1.86 \mathrm{~nm}$ and the tangent determined by three points - we have estimated the critical concentration which equals about $4.3 \%(\mathrm{v} / \mathrm{v})$ (Fig. 5). This result is close to the triggering value (about $5 \%(\mathrm{v} / \mathrm{v})$ ), when $B_{22}$ coefficient reaches the plateau value. The initial increase of $B_{22}$ indicates the increase of repulsive forces between protein molecules. The absorption of ethanol molecules on hydrophobic sites on the protein surface reduces the hydrophobic proteinprotein interactions. When ethanol concentration increases over the critical concentration, $R_{\mathrm{H}}$ starts to increase, which is related with structure transformation. We have observed an increase of partial specific volume (densitometry) and the increase of $\alpha$-helix content (CD data) [16].

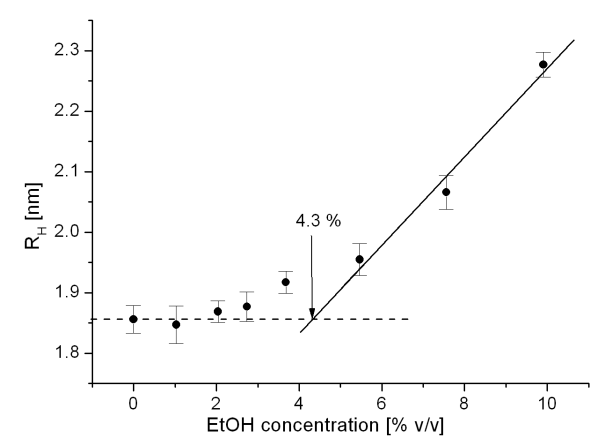

Fig. 5. Hydrodynamic radius $R_{\mathrm{H}}$ of lysozyme vs. ethanol concentration (calculated on the basis of data presented in Fig. 2).

More precise analysis could be performed using the methods of neutron crystallography. Among others the analysis of ethanol-lysozyme interaction has been per- formed for a single crystal of the protein soaked in $25 \%(\mathrm{v} / \mathrm{v})$ by ethanol solution [29]. The authors have determined three regions on the surface of lysozyme with the highest occupation of ethanol. These regions include amino acid residues 35-45, 57-72 (these two regions form $\beta$ domain) and 105-129 (at $\mathrm{C}$ terminal). Alcohol molecules did not affect the structure and thermal motion of the atoms in the protein. This means that, when the relative concentration of ethanol is low, the interaction between ethanol and the lysozyme molecule is weak, with a short occupation time. The structural transformation process starts when the mutual interactions between ethanol and lysozyme cause dehydration of the protein. Such conclusion could be drawn on the basis of X-ray studies which were performed recently by Deshpande and co-workers [30]. The authors co-crystallized lysozyme with various alcohols (alcohol concentration about $20 \%(\mathrm{v} / \mathrm{v})$ ), among others with ethanol and observed that there are two binding sites $(\mathrm{N}-$ and $\mathrm{C}$ terminal) in common for all kinds of alcohol molecules under consideration. Alcohol molecules replaced water molecules. According to other studies based on CD analysis [8], the major effect of alcohol as a co-solvent concerns reduction of hydration in the starting state and subsequent slight expansion of $\alpha$-helical substructures.

\section{References}

[1] M. Stefani, C.M. Dobson, J. Mol. Biol. 81, 678 (2003).

[2] V.N. Uversky, A.L. Fink, Biochim. Biophys. Acta 1698, 131 (2004).

[3] M.B. Pepys, P.N. Hawkins, D.R. Booth, D.M. Vigushin, G.A. Tennet, A.K. Soutar, N. Totty, O. Nguyen, C.C. Blake, C.J. Terry, T.G. Feest, A.M. Zalin, J.J. Hsuan, Nature 362, 553 (1993).

[4] A.J. Trexler, M.R. Nilsson, Curr. Prot. Pept. Sci. 8, 537 (2007).

[5] S. Goda, K. Takano, Y. Yamagata, R. Nagata, H. Akutsu, S. Maki, K. Namba, K. Yutani, Protein Sci. 9, 369 (2000).

[6] H.R.M. Krebs, K.D. Wilkins, W.E. Chung, C.M. Pitkeathly, K.A. Chamberlain, J. Zurdo, V.C. Ronibson, C.M. Dobson, J. Mol. Biol. 300, 541 (2000).

[7] A. Cao, D. Hu, L. Lai, Protein Sci. 13, 319 (2004).

[8] M. Holley, Ch. Eginton, D. Schaefer, L.R. Brown, Biochem. Biophys. Res. Commun. 373, 164 (2008).

[9] Y. Yonezawa, S. Tanaka, T. Kubota, K. Wakabayashi, K. Yutani, S. Fujiwara, J. Mol. Biol. 323, 237 (2002).

[10] B.J. Berne, R. Pecora, Dynamic Light Scattering, Wiley, New York 1976.

[11] S.J. Perkins, Biophys. Chem. 93, 129 (2001).

[12] N. Javid, K. Vogtt, Ch. Krywka, M. Tolan, R. Winter, Chem. Phys. Chem. 8, 679 (2007).

[13] J. Garcia de la Tore, Biophys. Chem. 93, 159 (2001).

[14] R.E. Canfield, J. Biol. Chem. 238, 2698 (1963).

[15] M.C. Vaney, S. Maignan, M. Ries-Kautt, A. Ducruix, Acta Crystallogr. D 52, 505 (1996). 
[16] A. Szymańska, Ph.D. Thesis, Adam Mickiewicz University, Poznań 2010.

[17] A.J. Sophianopoulos, C.K. Rhodes, D.N. Holcomb, K.E. Van Holde, J. Biol. Chem. 237, 1107 (1962).

[18] S.B. Dubin, N.A. Clark, G.B. Benedek, J. Chem. Phys. 54, 5158 (1971).

[19] G. Chirico, S. Beretta, G. Baldini, J. Chem. Phys. 110, 2297 (1999).

[20] V. Calandrini, D. Fioretto, G. Onori, A. Santucci, Chem. Phys. Lett. 324, 344 (2000).

[21] S. Tanaka, Y. Oda, M. Ataka, K. Onuma, S. Fujiwara, Y. Yonezawa, Biopolymers 59, 370 (2001).

[22] J. Gierszewski, G. Ślósarek, Mol. Phys. Rep. 41, 81 (2005).

[23] W. Liu, D. Bratko, J.M. Prausnitz, H.W. Blanch, Biophys. Chem. 107, 289 (2004).
[24] A. Bonincontro, V. Calandrini, G. Onori, Colloids Surf. $B$ 21, 311 (2001).

[25] D.F. Nicoli, G.B. Benedek, Biopolymers 15, 2421 (1976).

[26] S.B. Dubin, G. Feher, G.B. Benedek, Biochemistry 12, 714 (1973).

[27] Y. Georgalis, P. Umbach, J. Raptis, W. Saenger, Acta Crystallogr. D 53, 691 (1997).

[28] S. Arai, M. Hirai, Biophys. J. 76, 2192 (1999).

[29] M.S. Lehmann, S.A. Mason, G.J. McIntyre, Biochemistry 24, 5862 (1985).

[30] A. Deshpande, S. Nimsadkar, S.C. Mande, Acta Crystallogr. D 61, 1005 (2005). 